\title{
Ileocolonic anastomosis fecalith impaction in a patient with Crohn's disease: needle-knife stricturotomy and stone retrieval
}

Stasis of intestinal contents is a proposed mechanism for intestinal fecalith formation $[1,2]$. Obstruction and perforation requiring surgical intervention are reported in the literature as consequences of stercoral ulcers at the stone bed [2-4]. We present the case of an impacted anastomotic site fecalith removed after needleknife stricturotomy treatment of the mucosa ( $\bullet$ Video 1$)$.

A 71-year-old woman with a 41-year history of Crohn's disease complicated by two small-bowel resections in 1978 presented with a complaint of right lower quadrant pain, loose stools, and a prior diagnosis of a "mass" in her small bowel since 2012. She denied any weight loss, night sweats, fevers, or nonsteroidal antiinflammatory drug use.

Colonoscopy identified a fecalith occluding the neoterminal ileum lumen ( $\bullet$ Fig. 1). A 3-cm Roth net (US Endoscopy, Mentor, Ohio, USA) was used to try to pull the fecalith out, but multiple attempts at this were unsuccessful as the net continued to slip off the fecalith ( Fig.2). Next, a 5-mm needle-knife (Boston Scientific, Natick, Massachusetts, USA) was loaded into the colonoscope and used to perform a stricturotomy on the luminal side of the anastomosis mucosal wall $(\bullet$ Fig.3). Once the mucosal wall was cut, a reusable endoscopic basket (Boston Scientific, Natick, Massachusetts, USA) was used to retrieve the stone ( $\bullet$ Fig. 4). The stone was withdrawn into the patient's rectum, and after bearing down she passed the $3.8 \times 3.6-\mathrm{cm}$ stone as a bowel movement. The colonoscope was reinserted into the colon and advanced to the terminal ileum, where clips were placed along the cut mucosal wall ( $\bullet$ Fig.5).

Endoscopy_UCTN_Code_TTT_1AQ_2AF

Competing interests: None

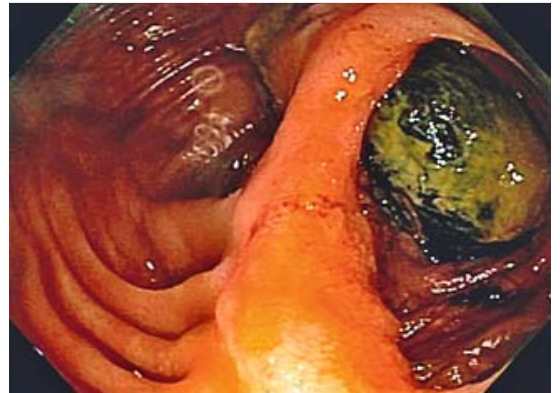

Fig. 1 Impacted fecalith at the site of ileocolonic anastomosis in a 71-year-old woman with Crohn's disease.

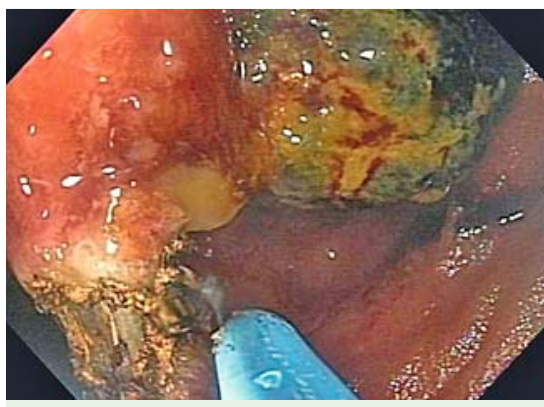

Fig.3 Needle-knife stricturotomy to the bowel wall at the site of impaction.

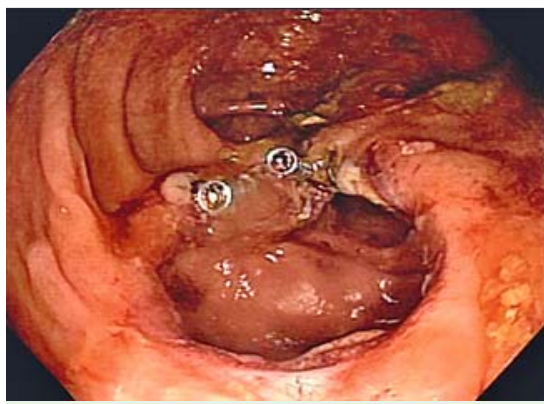

Fig. 5 Bowel wall after treatment with needle-knife stricturotomy, stone retrieval, and clip placement.

\section{Vivian Chidi, Abigail Oberc, Bo Shen}

Cleveland Clinic Foundation, Cleveland, Ohio, United States

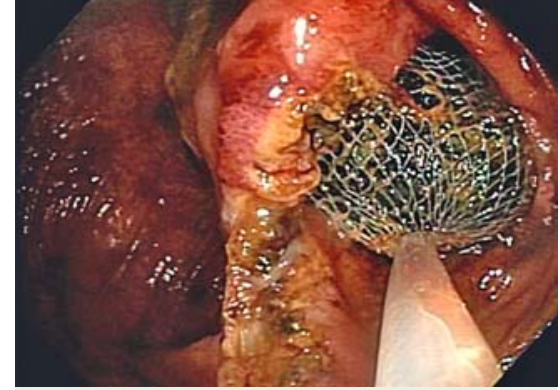

Fig.2 Attempts at Roth net retrieval of the fecalith, which were unsuccessful.

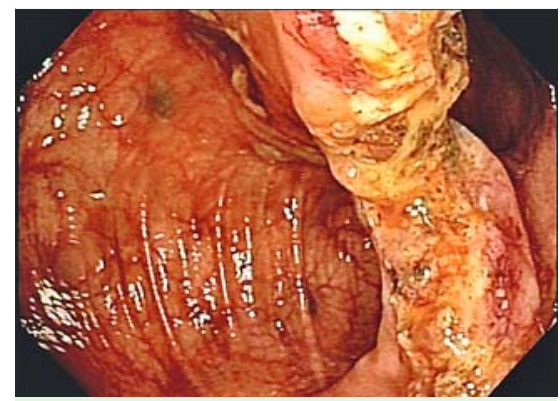

Fig.4 Bowel wall after needle-knife stricturotomy and stone retrieval.

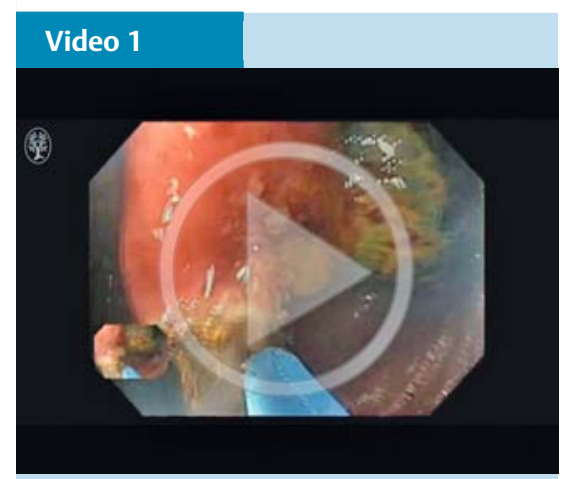

Needle-knife stricturotomy and retrieval of a fecalith at the site of ileocolonic anastomosis in a 71-year-old woman with Crohn's disease. 


\section{References}

1 Huiying $Z$, Ye L, Dianbo C. Submucosal fecalith in the ileocecal valve. Gastrointest Endosc 2014; 80: 1183-1184

2 Javors B, Bryk D. Enterolithiasis: a report of four cases. Gastrointest Radiol 1983; 8: 359-362

3 Russell W. Stercoraceous ulcer. Am Surg 1976; 42: 416-420

4 Badruddoja M, Jury D, Witter J. Intestinal obstruction by a fecalith in a Meckel's diverticulum. Can J Surg 1968; 11: 385-387

\section{Bibliography}

DOI http://dx.doi.org/

10.1055/s-0042-120262

Endoscopy 2016; 48: E388-E389

(c) Georg Thieme Verlag KG

Stuttgart · New York

ISSN 0013-726X

\section{Corresponding author}

Bo Shen, MD

The Interventional IBD (i-IBD) Unit

Digestive Disease and Surgery Institute - A31

The Cleveland Clinic Foundation

9500 Euclid Avenue

Cleveland

$\mathrm{OH} 44195$

USA

Fax: +1-216-444-6305

shenb@ccf.org 